\title{
Interleukin- $1 \beta$ regulates the expression of glucocorticoid receptor isoforms in nasal polyps in vitro via p38 MAPK and JNK signal transduction pathways
}

\author{
Zhenlin Wang ${ }^{1}$, Peng Li ${ }^{2}$, Qiuhang Zhang ${ }^{1 *}$, Haili Lv' ${ }^{1}$ Junqi Liư ${ }^{1}$ and Jinyuan $\mathrm{Si}^{1}$
}

\begin{abstract}
Background: To explore the upstream signal transduction mechanisms responsible for the imbalanced expression of glucocorticoid receptor (GR) isoforms in chronic rhinosinusitis (CRS) mucosa.

Methods: An in vitro model of Glucocorticoid resistance was established by inducing nasal polyp tissue with IL-1 $\beta$. Changes in the protein and mRNA expression of GRa, GRß and the key enzymes in the p38 MAPK and JNK signal pathways were measured, respectively, before and after being induced with different doses of IL-1 $\beta$ and specific inhibitors of p38 MAPK, JNK, ERK, PI3K and PKC. The Glucocorticoid sensitivity was measured using in vitro Glucocorticoid binding assay. Analysis of variance (ANOVA) was used to analyze the data.

Results: The mRNA and protein expression levels of GRa, GRß and key enzymes of the p38 MAPK and JNK pathways increased both in time- and concentration-dependent manners in IL-1 $\beta$-induced nasal polyp tissue. The expression of GRß increased more significantly than that of $G R a$, and the $G R a / G R \beta$ ratio decreased in time- and concentration-dependent manners. Statistically significant differences were found in the GRa/GRß ratio and the mRNA expression of phospho-p38 MAPK and phospho-JNK between the IL-1 $\beta$-induced groups and the control groups $(P<0.05)$. Either a specific inhibitor of the p38 MAPK pathway or a specific inhibitor of the JNK pathway increased the $\mathrm{GRa} / \mathrm{GR} \beta$ ratio and the Glucocorticoid affinity. None of the specific inhibitors of ERK, PI3K or PKC had any influence on the expression of GR isoforms.
\end{abstract}

Conclusion: Our results demonstrated that the imbalanced expression of GR isoforms in nasal polyp tissue induced by $\mathrm{IL}-1 \beta$ in vitro is mediated through the P38 MAPK and JNK signal pathways.

Keywords: Chronic rhinosinusitis (CRS), Nasal polyp (NP), Signal transduction, Mitogen-activated protein kinase (MAPK)

\section{Background}

Chronic rhinosinusitis (CRS) is a chronic inflammatory disease that involves the mucosa of the nasal cavity and sinus and has a $2-15 \%$ incidence rate worldwide [1,2]. Glucocorticoid (GC) therapy is widely used to control mucosal inflammation in CRS cases and to slow the growth of nasal polyps [3-5]. Although GC treatment is effective in the majority of CRS cases, there are still

\footnotetext{
* Correspondence: shengxuewuyan@hotmail.com

'Department of Otolaryngology-Head and Neck Surgery, Xuan Wu Hospital, Capital Medical University, 45 Changchun Street, Xicheng District, Beijing 100053, PR China

Full list of author information is available at the end of the article
}

some patients who fail to respond to GC treatment, even at high doses or with supplementary therapies. This phenomenon is termed GC resistance.

The biological action of GC is mediated through the activation of intracellular glucocorticoid receptors (GR). There are two human GR isoforms (GR $\alpha$ and GR $\beta$ ), and GC's physiological actions are mainly mediated by GR $\alpha$, which is far more abundant than GR $\beta$ in nasal mucosa $[6,7]$. GR $\beta$ negatively regulates GR $\alpha$ by forming GR $\alpha /$ GR $\beta$ heterodimers, reducing the anti-inflammatory effect of GC $[8,9]$. Recent studies have clearly demonstrated that a higher expression of GR $\beta$ led to a lower GR $\alpha / G R \beta$ ratio in the nasal polyps of GC-resistant CRS cases than 
in GC-sensitive nasal polyps, indicating that, to a certain extent, the imbalanced expression of the GR isoforms determines the anti-inflammatory effect of GC therapy and is one of the important factors contributing to GC resistance in CRS [10-12]. However, the detailed mechanism responsible for the GR isoform expression imbalance in the mucosa of GC-resistant CRS cases has not been clearly defined, and merits further investigation.

Recent studies [13-15] have suggested that the abnormal expression of GR isoforms may be related to certain key enzymes in the mitogen activated protein kinase (MAPK) family. However, there has been no discussion about the exact MAPK family signal pathways that may regulate the $\mathrm{GR}$ expression in the mucosa of $\mathrm{GC}$ resistant $\mathrm{CRS}$, altering the $\mathrm{GR} \alpha / \mathrm{GR} \beta$ ratio and thereby changing the GC sensitivity of the inflamed nasal mucosa. This study has been designed to explore the upstream signal transduction mechanisms responsible for lowering the $\mathrm{GR} \alpha / \mathrm{GR} \beta$ ratio. In this study, a $\mathrm{GC}$ resistance model of nasal polyps induced by interleukin-1 beta $(\mathrm{IL}-1 \beta)$ in vitro was developed to measure the relationship between the expression of GR isoforms and p38 MAPK and JNK signal transduction pathways.

\section{Methods}

\section{Reagents}

Primary monoclonal antibodies against GR $\alpha, G R \beta$, phospho-p38MAPK, phospho-JNK and $\beta$-actin, as well as a horseradish peroxidase-labeled secondary goat anti-mouse IgG antibody, were purchased from Santa Cruz Biotechnology (USA). IL-1 $\beta$ was purchased from PeproTech (England) and RPMI1640 culture medium was purchased from GIBCO (USA). The specific inhibitors of the p38 MAPK pathway (SB203580), ERK pathway (PD98059), PI3K pathway (LY294002), PKC pathway (Ro31-8220) and JNK pathway (SP600125) were all purchased from Calbiochem (USA). $\left[{ }^{3} \mathrm{H}\right]$-Dexamethasone was obtained from Amersham (USA). Dexamethasone was purchased from Sigma (USA). The primers and Taqman probes targeting GR $\alpha$, GR $\beta$, p38 MAPK and JNK were designed and synthesized by Applied Biosystems (USA). All other chemicals used in the study were of analytical grade and obtained from commercial sources.

\section{Ethics statement}

This study received approval from the ethics committee of the Capital Medical University. All patients signed an informed consent form that had been preapproved by the ethics committee.

\section{Sample collection}

Nasal polyp tissues were taken from 15 CRS with nasal polyp patients (6 male, 9 female, aged $41 \pm 5$ years) who had been admitted to our hospital between March 2011 and June 2011. The patients were each found to have had CRS with nasal polyps for between 8 and 22 months and had received conservative treatment (topical steroid and nasal douching) for 12 weeks based on the standard criteria for CRS with nasal polyps issued in the European Position Paper on Rhinosinusitis and Nasal Polyps 2007 guidelines [16]. On the basis of the immunohistochemical findings, all of the cases were defined as having eosinophil-high inflammation, which, according to the method described by Jankowski [17], was sensitive to GC. Our specimens were obtained during endoscopic surgeries. At the time the specimens were obtained, none of the patients was affected by, nor had they in the last six months been affected by any of the following problems: nasal polyposis, allergic rhinitis, asthma, kidney disease, rheumatoid arthritis, myasthenia gravis, or any infectious diseases; they had not undergone sinus surgery over the last six months; and none of the patients had any history of smoking. All patients suspended the use of angiotensin-converting enzyme inhibitors, betaagonists and glucocorticoids in the two months prior to their surgery.

\section{Tissue culturing and intervention}

Nasal polyp tissue was cultured according to the reported method [18]. Briefly, all tissue samples were rinsed 5 or 6 times with stroke-physiological saline solution containing penicillin and streptomycin, and each nasal polyp tissue sample was divided into several tissue blocks (approximately $4 \mathrm{~mm} \times 4 \mathrm{~mm}$ in size) containing mucous layers. The tissue blocks were then transferred to 6-well culture plates with $1.5 \mathrm{ml}$ RPMI1640 medium (supplemented with $10 \%$ fetal bovine serum) and were cultured at $37^{\circ} \mathrm{C}$ in an atmosphere of $5 \% \mathrm{CO}_{2}$ for $24 \mathrm{~h}$. The cultured tissue blocks were taken out and divided into several different experiment groups. Each group of samples was exposed to different concentrations of IL-1 $\beta$ with or without the presence of specific inhibitors of MAPK family signal pathways. Two replicate samples from each group were harvested and preserved immediately. One of the two samples was used for protein concentration measurement. The nasal polyp tissue was treated with lysis buffer $(150 \mathrm{mM} \mathrm{NaCl}, 1 \%$ Triton X-100, 0.5\% deoxycholate, $0.1 \%$ SDS, and $50 \mathrm{mM}$ Tris- $\mathrm{HCl}, \mathrm{pH}$ 7.5) supplemented with a complete protease inhibitor cocktail (Roche Diagnostics; USA) and preserved for Western blot analysis (described below). Protein concentration was measured by the Bradford method. The second sample was used for RNA measurement. Total RNA from the second sample was isolated and preserved at $-80^{\circ} \mathrm{C}$ for the fluorescent quantitative reverse transcription polymerase chain reaction (FQ-RT-PCR) assay described below. For the control group, all steps were the same with the only exception being that all nasal polyp 
tissues were incubated with medium alone for the same length of time.

\section{Western blot}

An equal amount of denatured proteins $(50 \mu \mathrm{g})$ was separated in a $12 \%$ SDS-polyacrylamide gel $(90 \mathrm{~V}, 1.5 \mathrm{~h})$ and transferred to a nitrocellulose membrane (Millipore; USA) ( $90 \mathrm{~V}, 1.5 \mathrm{~h}$ ). This membrane was then blocked for $2 \mathrm{~h}$ at room temperature in $5 \%(\mathrm{w} / \mathrm{v})$ non-fat dried milk dissolved in a Tris-buffered saline [10 mM Tris (pH 8.0) and $150 \mathrm{mM} \mathrm{NaCl}$ ] solution containing $0.05 \%$ Tween-20. Following this, the membrane was incubated for $1.5 \mathrm{~h}$ at room temperature with the indicated primary antibodies (1:500). The membrane was then incubated with the corresponding horseradish peroxidase-labeled secondary goat anti-mouse IgG antibodies. Immunoreactive proteins were measured with the Enhanced Chemiluminescence (ECL) Western blot detection system (Millipore; USA). The $\beta$-actin protein served as an endogenous loading control.

\section{FQ-RT-PCR}

Total RNA was reversely transcribed to cDNA using oligo (dT) 18 primers, and PCR amplifications of GR $\alpha$, GR $\beta$, p38 MAPK and JNK were performed with TaqMan universal master mix. The end products were quantified with an ABI 7900 sequence detector. Each reaction contained $25 \mu \mathrm{l} 2 \times$ Taqman PCR master, $1 \mu \mathrm{l}$ upstream primer $(10 \mu \mathrm{M}), 1 \mu \mathrm{l}$ downstream primer $(10 \mu \mathrm{M}), 1 \mu \mathrm{l}$

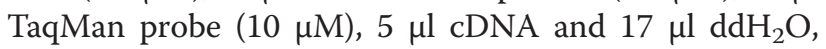
with a total solution volume of $50 \mu$ l. The thermocycler parameters were set as: $95^{\circ} \mathrm{C}$ for $10 \mathrm{~min}$, followed by 40 cycles of $95^{\circ} \mathrm{C}$ for $30 \mathrm{~s}$ and $60^{\circ} \mathrm{C}$ for $45 \mathrm{~s}$. All reactions were carried out in triplicate. The relative quantity of mRNA was determined using the comparative cycle threshold method, and values were normalized using $\beta$-actin as an endogenous control. The primers and probes employed were as follows: GR $\alpha, 5^{\prime}$-TGA AAA TGG GTT GGT GCTT CTA-3' (upstream), 5'-GAC AAG AAT ACT GGA GAT TTG AGT CAA-3' (downstream), 5'-FAM-CCT GAT GGC ACT TAG CTA TCA GAA GAC CAC AA-TAMRA-3' (probe); GR $\beta, 5^{\prime}$-TGG CCA CCC CAA AAG GA-3' (upstream), 5'-GAG CTC ATC CCA TGC TAA TTA TCC-3' (downstream), 5'-FAM-AAC TAA CAT GAT TTG TGT CTA TGA AGT GC-TAMR A -3' (probe); p38MAPK, 5'-GGC TCT GGC GCC TATG G-3' (upstream), 5'-CCA CAC GTA ACC CCG TTT TT-3' (downstream), 5'-FAM-TCT GTG TGT GCT GCT TTT GAC A-TAMRA-3' (probe); JNK, 5'-TAC AGA GCA CCC GAG GTC ATC-3' (upstream), 5'-AGA GGA TTT TGT GGC AAA CCA-3' (downstream), 5'-FAM-TGG CAT GGG CTA CAA GGA AAA CG-TAMRA-3' (probe); $\beta$-actin, 5'-TCC CTG GAG AAG AGC TAC GAG-3' (upstream), 5'-GCC GTG ATC
TCC TTC TGC A-3' (downstream), 5'-FAM- CGC TCT TCC AGC CCT CCT TCC TGG-TAMRA-3' (probe).

\section{GC binding assay}

$\left[{ }^{3} \mathrm{H}\right]$ dexamethasone binding assay has been used in several previous studies $[19,20]$ to determine GC affinity. This assay was carried out in this research as previously reported. In brief, the polyp tissue blocks were homogenated 3 times and the resulted nasal polyp homogenate was centrifugated $(12000 \mathrm{r} / \mathrm{min})$ for $20 \mathrm{~min}$. The homogenate was then isolated and washed 3 times to remove endogenous cortisol before being exposed to $\left[{ }^{3} \mathrm{H}\right]$ dexamethasone ranging between different concentrations (the range 1-50 nM), with or without a 1,000-fold excess unlabelled dexamethasone. Radioactivity was measured in liquid scintillation vials. Specific binding was calculated by subtracting nonspecific binding from the total binding. The equilibrium dissociation constant $(\mathrm{Kd})$ was calculated using SCATCHARD method (by the slope of the curve in the Scatchard plot).

\section{Statistical analysis}

Statistical analysis was carried out using the SPSS Version 16.0 software package. Data sets for a given construct were pooled and averaged. The statistical significance of the difference between control and experimental data sets was determined by analysis of variance (ANOVA) with the least significant difference (LSD) test. Differences with $P$-values less than 0.05 were considered to be statistically significant.

\section{Results}

Establishment of a GC resistance model of nasal polyps induced by IL- $1 \beta$ in vitro

IL-1 $\beta$ induced a decrease in the GR $\alpha / G R \beta$ ratio in a dosedependent manner in cultured nasal polyps in vitro.

After having been cultured in the presence of $0 \mathrm{ng} /$ $\mathrm{mL}, 10 \mathrm{ng} / \mathrm{mL}, 20 \mathrm{ng} / \mathrm{mL}$ and $30 \mathrm{ng} / \mathrm{mL} \mathrm{IL}-1 \beta$ for $20 \mathrm{~h}$ respectively, samples were harvested and GR $\alpha$ and GR $\beta$ protein expressions were measured. Low expression of GR $\alpha(94 \mathrm{kDa})$ and $\mathrm{GR} \beta(90 \mathrm{kDa})$ was detected by using Western blot in the cultured nasal polyp tissue of the control group ( $0 \mathrm{ng} / \mathrm{mL} \mathrm{IL-1 \beta})$, and it showed that the expression level of GR $\beta$ was lower than that of GR $\alpha$ (Figure $1 \mathrm{~A}$ and $\mathrm{B}$ ). The mRNA and protein expression of GR $\alpha$ and GR $\beta$ in the IL- $1 \beta$-induced nasal polyp tissues increased in a concentration-dependent manner (depending on IL-1 $\beta$ concentration), and the expression of GR $\beta$ increased more significantly than that of GR $\alpha$ (Figure $1 \mathrm{~A}, \mathrm{~B}$ and $\mathrm{C}$ ). The $\mathrm{GR} \alpha / \mathrm{GR} \beta$ ratio decreased in a concentration-dependent manner in nasal polyp tissue induced by IL-1 $\beta$ (Figure 1D). The GR $\alpha / G R \beta$ ratio of each treatment group at the mRNA and protein 

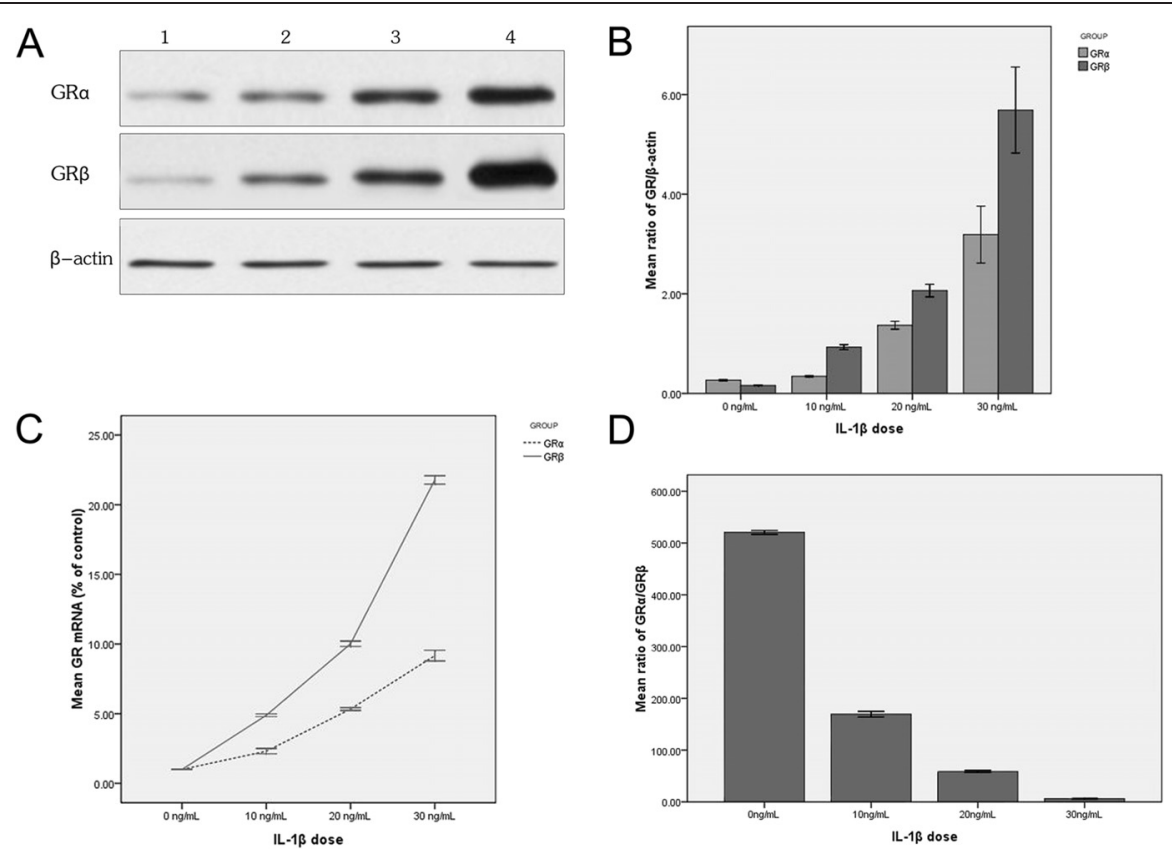

Figure 1 The expression of GR isoforms induced by IL-1 $\beta$ of different doses in vitro. A represents Western blot results of IL-1 $\beta$-induced protein expression of GR isoforms. Lanes $1-4$ represent the GR expression in $0 \mathrm{ng} / \mathrm{mL}, 10 \mathrm{ng} / \mathrm{mL}, 20 \mathrm{ng} / \mathrm{mL}$ and $30 \mathrm{ng} / \mathrm{mL} \mathrm{IL}-1 \beta$-treated groups respectively. The GRa and GRB expression increased with higher IL-1 $\beta$ dosage. $\mathbf{B}$ represents the densitometry value (Western blot bands in 1A) ratio of GR isoforms and $\beta$-actin. The protein expression of GRa and GR $\beta$ increased with the increase of IL-1 $\beta$ dosage, and the GR $\beta$ expression increased more significantly than the GRa expression. $\mathbf{C}$ represents the mRNA ratio of GR isoforms in IL-1 $\beta$-induced group and the control group $(0 \mathrm{ng} / \mathrm{mL})$. The mRNA expression of GRa and GRß increased with the increase of $\mathrm{LL}-1 \beta$ dosage, and the GR $\beta$ expression increased more significantly than the GRa expression. D represents the GRa/GRß mRNA expression (measured by FQ-RT-PCR) ratio induced by IL-1 $\beta$. The GRa/GR $\beta$ ratio decreased with the increase of $\mathrm{IL}-1 \beta$ dosage in nasal polyp tissue. The data presented above are the means ( $\pm \mathrm{SD}$ ) of three independent experiments with similar trend.

levels was significantly lower than that of the control group $\left(X^{2}=36.031, P=0.001 ; X^{2}=27.533, P=0.001\right)$.

IL-1 $\beta$ induced a decrease in the GR $\alpha / G R \beta$ ratio in a time-dependent manner in cultured nasal polyps in vitro.

Nasal polyp tissues were cultured in the presence of $20 \mathrm{ng} / \mathrm{mL} \mathrm{IL}-1 \beta$ for $0 \mathrm{~h}, 10 \mathrm{~h}, 20 \mathrm{~h}$ and $30 \mathrm{~h}$ respectively. IL-1 $\beta$ induced the expression of GR $\alpha$ and GR $\beta$ in a timedependent manner, and the expression of GR $\beta$ increased more significantly than that of GR $\alpha$ (Figure $2 A, B$ and $C$ ). IL- $1 \beta$ treatment led to lower GR $\alpha / G R \beta$ ratio in a timedependent manner (Figure 2D). The GR $\alpha / G R \beta$ ratio at the mRNA and protein levels observed in each treatment group was significantly lower than that of the control group $\left(X^{2}=52.321, P=0.002 ; X^{2}=38.742, P=0.001\right)$.

The same set of IL- $1 \beta$ concentrations also induced an activation of p38 MAPK and JNK signal pathways in a similar dose-dependent manner.

$0 \mathrm{ng} / \mathrm{mL}, 10 \mathrm{ng} / \mathrm{mL}, 20 \mathrm{ng} / \mathrm{mL}$ and $30 \mathrm{ng} / \mathrm{mL}$ of IL- $1 \beta$ were used to induce nasal polyp tissues for $20 \mathrm{~h}$ in vitro respectively. Both phospho-p38 MAPK (39 kDa) and phospho-JNK (46 kDa/54 kDa) protein and mRNA were extracted for quantitative measurements. A low expression of phospho-p38 MAPK and phospho-JNK was observed in the control group. IL-1 $\beta$ led to higher phospho-p38 MAPK and phospho-JNK expression at the protein (Figure $3 \mathrm{~A}$ and $\mathrm{B}$ ) and mRNA (Figure $3 \mathrm{C}$ ) levels in a concentration-dependent manner in nasal polyp tissues in vitro. The mRNA and protein expression of p38 MAPK and JNK in each IL-1 $\beta$-induced group was significantly higher than that in the control group $\left(X^{2}=18.071, P=0.001\right.$; $X^{2}=17.371, P=0.002 ; X^{2}=21.913, P=0.001 ; X^{2}=33.652$, $P=0.001$ ).

It was found that $\mathrm{p} 38$ MAPK and JNK pathways but not PI3K, ERK or PKC were responsible for the regulation of the GR $\alpha / G R \beta$ ratio and GC affinity in IL-1 $\beta$-induced polyps.

Specific inhibitors (SB203580 and SP600125) of the p38 MAPK or JNK signal pathways were separately added (at a dose of $5 \mu \mathrm{M}$ ) to the culture medium $30 \mathrm{~min}$ before the induction with $20 \mathrm{ng} / \mathrm{mL}$ IL- $1 \beta$. The expressions of GR isoforms, phospho-p38 MAPK and phospho-JNK were measured $20 \mathrm{~h}$ after IL-1 $\beta$ induction (Figure 4 ). The results showed that $5 \mu \mathrm{M}$ SB203580 (a specific inhibitor of p38 MAPK) significantly lowered the expression of phospho-p38 MAPK, while the expression of phosphoJNK did not differ from that in the control group $(0 \mu \mathrm{M}$ SB203580). Meanwhile, the expressions of GR $\alpha$ and GR $\beta$ also decreased, with GR $\beta$ expression having decreased 

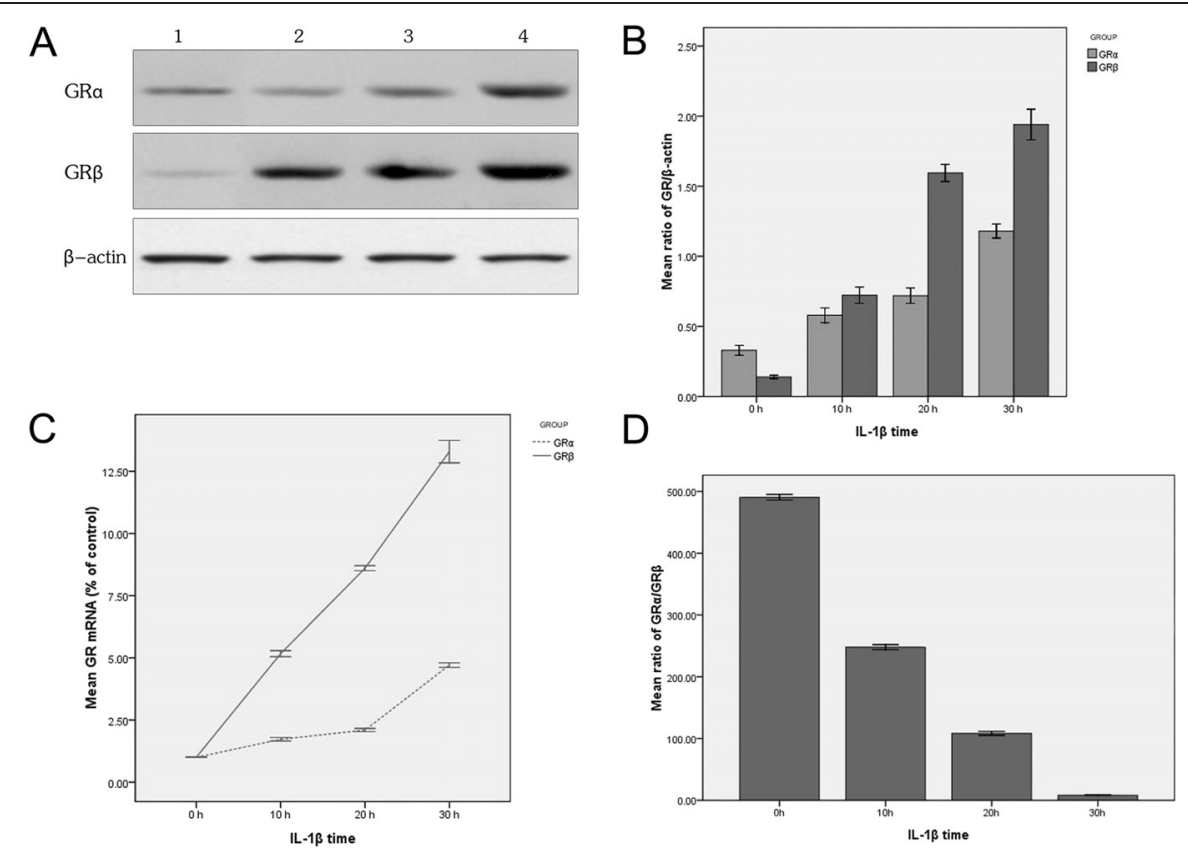

Figure 2 The expression of GR isoforms induced by IL-1 $\beta$ with different time length in vitro. A represents Western blot results of IL-1 $\beta$ induced protein expression of GR isoforms. Lanes 1-4 represent the expression in sample groups treated with IL-1 3 -treated for $0 \mathrm{~h}, 10 \mathrm{~h}, 20 \mathrm{~h}$ and $30 \mathrm{~h}$ respectively. The GRa and GRB expression increased with longer IL-1 $\beta$-inducing time. $\mathbf{B}$ represents the densitometry value (Western blot bands in $2 A$ ) ratio of $G R$ isoforms and $\beta$-actin. The protein expression of $G R a$ and $G R \beta$ increased as the IL-1 $\beta$-inducing time was increased, and the GRß expression increased more significantly than the GRa expression. C represents the ratio of GR isoforms mRNA between IL-1 $\beta$ induced groups and the control group ( $0 \mathrm{~h}$ ). The mRNA expression of GRa and GR $\beta$ increased as the IL-1 $\beta$-inducing time was increased, and the GR $\beta$ expression increased more significantly than the GRa expression. $\mathbf{D}$ represents the GRa/GR $\beta$ mRNA expression (measured by FQ-RT-PCR) ratio induced by IL-1 $\beta$. The GRa/GR $\beta$ ratio decreased with the increase of IL-1 $\beta$-inducing time in nasal polyp tissue. The data presented are means $\pm S D$ of three independent experiments with similar trend.

more significantly leading to a higher $\mathrm{GR} \alpha / \mathrm{GR} \beta$ ratio. The GR $\alpha / G R \beta$ ratio in the SB203580-treated group was significantly higher than that of the control group $\left(X^{2}=17.431\right.$, $P=0.001$ ). Treatment with $5 \mu \mathrm{M}$ SP600125 (specific inhibitor of JNK) lead to significantly lower expression of phospho-JNK, while the expression of phospho-p38 MAPK was not found to be significantly different from that in the control group $(0 \mu \mathrm{M} \mathrm{SP600125).} \mathrm{It} \mathrm{was} \mathrm{found}$ that the expressions of GR $\alpha$ and GR $\beta$ also decreased, with the GR $\alpha / G R \beta$ ratio of the $5 \mu \mathrm{M}$ SP600125 group significantly higher than that of the control group $\left(X^{2}=18.071\right.$, $P=0.001$ ). Further, SB203580 exhibited a much stronger inhibitive effect on GR $\alpha$ and GR $\beta$ expressions than SP600125 (Figure 4A and B). After both SB203580 and SP600125 were added simultaneously to the medium with IL-1 $\beta$ induction, almost all expressions of GR $\alpha$ and GR $\beta$ were inhibited (Figure 4A and B). Moreover, incubation with $5 \mu \mathrm{M}$ SB203580 or $5 \mu \mathrm{MSP} 600125$ without IL-1 $\beta$ induction did not reveal in changes the GR isoform expressions at all. Specific inhibitors (LY294002, PD98059 or Ro31-8220) of the PI3K, ERK or PKC signal pathways were added separately (at a dose of $20 \mu \mathrm{M}$ ) to the culture medium $30 \mathrm{~min}$ before they were induced with $20 \mathrm{ng} / \mathrm{mL}$ IL-1 $\beta$. The expressions of GR isoforms in LY294002,
PD98059 or Ro31-8220 treated groups were not found to be significantly different from that in the $20 \mathrm{ng} / \mathrm{mL}$ IL-1 $\beta$ induced group (Figure 4A and B). The trend of GR $\alpha$ and GR $\beta$ mRNAs demonstrated the same patterns as that of those proteins in the above experiments (data not shown). In addition, GC affinity and sensitivity were determined by GC binding assay. GC affinity for $20 \mathrm{ng} / \mathrm{mL}$ IL- $1 \beta$ group $(\mathrm{Kd}=20.89 \pm 1.54)$ dropped more significantly than that for the control group $(\mathrm{Kd}=4.45 \pm 0.54$, $P<0.01)$. Our results also showed that the GC affinity and sensitivity increased after the nasal polyp was incubated with SB203580 $(\mathrm{Kd}=8.05 \pm 1.36, P<0.01)$ or SP600125 $(\mathrm{Kd}=12.40 \pm 1.83, \quad P<0.01)$, but did not change when incubated with LY294002, PD98059 or Ro31-8220 ( $\mathrm{Kd}=20.76 \pm 1.89, P>0.05)$.

\section{Discussion}

A decrease in the $G R \alpha / G R \beta$ ratio in nasal polyps is one of the important features of GC-resistant CRS. However, its etiology has remained unexplained, and there is currently no direct and effective treatment for GC-resistant CRS. In this study, IL-1 $\beta$ was used to induce cultured nasal polyp tissues in vitro. With the IL-1 $\beta$ induction, the GR $\alpha /$ GR $\beta$ ratio declined in both a time-dependent manner and a 


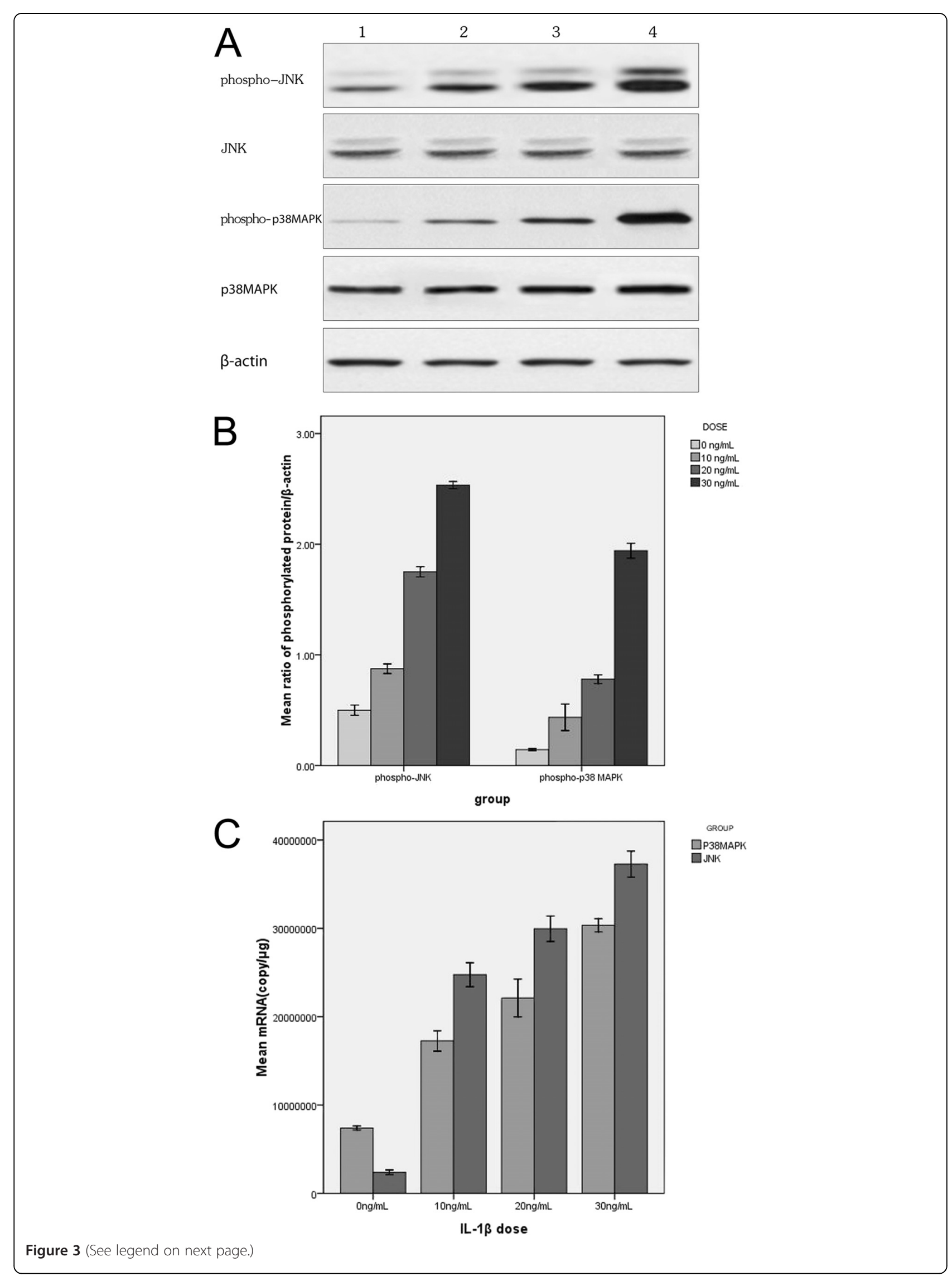


(See figure on previous page.)

Figure 3 P38 MAPK and JNK expression induced by IL-1 $\beta$ of different doses in vitro. A represents Western blot results of IL-1 1 -induced protein expression. Lanes 1-4 represent the expression in the groups treated with $\mathrm{IL}-1 \beta 0 \mathrm{ng} / \mathrm{mL}, 10 \mathrm{ng} / \mathrm{mL}, 20 \mathrm{ng} / \mathrm{mL}$ and $30 \mathrm{ng} / \mathrm{mL}$ respectively. The expression of phospho-p38 MAPK and phospho-JNK increased as the IL-1 $\beta$ dosage was increased. $\mathbf{B}$ represents the densitometry value (Western blot bands in 3A) ratio of phospho-p38 MAPK, phospho-JNK and $\beta$-actin. The expression of phospho-p38 MAPK and phospho-JNK increased as the IL-1 $\beta$ dosage was increased. C represents FQ-RT-PCR results of IL-1 $\beta$-induced mRNA expressions of p38 MAPK and JNK with similar trends as protein expressions. The data presented are means ( \pm SD) of three independent experiments with similar trend.

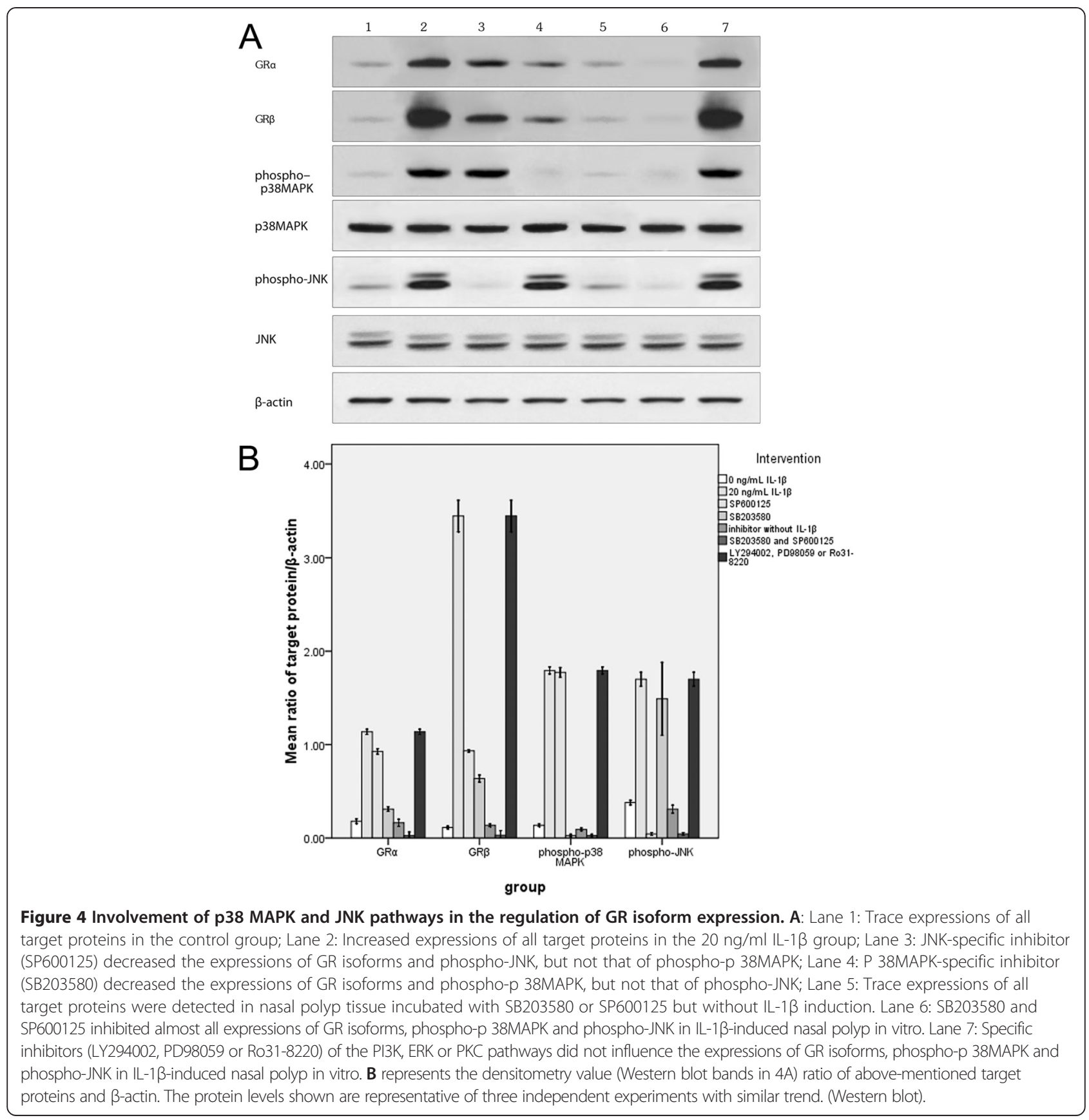


concentration-dependent manner, which demonstrates the successful establishment of a GR $\alpha / G R \beta$ imbalance model in vitro. We also found that after cultured nasal polyps were induced with the same set of IL- $1 \beta$ concentrations, the p38 MAPK and JNK signal pathways were also activated, as the expression of key enzymes of both pathways increased in a similar concentration-dependent manner. Furthermore, the intervention with specific inhibitors of the p38 MAPK and JNK pathways resulted in an increased GR $\alpha / G R \beta$ ratio and a recovery of GC affinity in IL- $1 \beta$ induced polyps. These results suggest that the p38 MAPK and JNK signal pathways may play an important role in the IL-1 $\beta$-induced GR $\alpha / G R \beta$ imbalance in nasal polyps and may be related to $\mathrm{GC}$ resistance in nasal polyps. Our results also suggest that blocking these signal pathways may lead to a recovery of GC sensitivity in GC resistance nasal polyps.

IL-1 $\beta$ is one of the important cytokines involved in the etiology of nasal mucosal inflammation. Histological studies have revealed that its expression increased in the mucosa and sinus secretions of rhinosinusitis patients, and this cytokine was confirmed to be associated with rhinosinusitis [21,22]. In our own study, we found that IL- $1 \beta$ could induce a reduction of the GR $\alpha / G R \beta$ ratio in dose- and time-dependent manners in cultured nasal polyps in vitro. Further, the expression of GR $\beta$ increased more than GR $\alpha$ at the mRNA and protein levels, suggesting that the increase in GR $\beta$ synthesis is the main cause of the decreased GR $\alpha / G R \beta$ ratio induced by IL- $1 \beta$ in vitro. Our results are consistent with other reported results based on GC resistance models involving human pulmonary epithelial cells, spleen cell and intestinal epithelial cell lines induced by IL-1 $\beta$ in vitro [23-25].

Although recent studies have confirmed that the decreased $G R \alpha / G R \beta$ ratio is one of the important features in GC-resistant CRS, the signal transduction mechanism responsible has not yet been fully identified, meaning that further research is needed. Before now, it has been suggested that p38 MAPK and JNK are involved in the signal transduction of GR. This study examined the activation of the p38 MAPK and JNK signal pathways in the IL-1 $\beta$-induced samples, and found that the expression of activated key enzymes (phospho-p38 MAPK or phospho$\mathrm{JNK}$ ) increased in the same manner as the GR $\beta / G R \alpha$ ratio. The above results suggest that the p38 MAPK and JNK signal pathways may be associated with the change of GR $\alpha / G R \beta$ ratio. Furthermore, the ratio of GR $\alpha / G R \beta$ and GC affinity were observed to increase after the p38 MAPK or JNK pathways were blocked by specific inhibitors, SB203580 and SP600125, respectively, indicating that the p38 MAPK and JNK signal pathways are indeed involved in regulating the ratio of GR isoforms and GC sensitivity in IL-1 $\beta$-induced nasal polyp tissues in vitro. In order to further exclude the possibility of SB203580 or SP600125 directly affecting GR isoform expression, we performed a negative control experiment (samples not induced with IL-1ß). Neither SB203580 nor SP600125 led to changs in GR isoform expression in this negative control experiment. The above results show that the synthesis of GR isoforms may be regulated through p38 MAPK and JNK signal pathways in the IL- $1 \beta$ induced nasal polyps. We believe that the change in the GR $\alpha / G R \beta$ ratio may cause the insensitivity of nasal polyps to GC. Blocking the above signal pathways helped to increase the $G R \alpha / G R \beta$ ratio, which may improve GC sensitivity in nasal polyps. Our results are consistent with recent studies reported by other researchers on the signal pathways involved with GR expression and GC sensitivity in brain tissue [26].

Although our study showed that both the p38 MAPK and JNK signal pathways were involved in the regulation of GR isoform expression in IL-1 $\beta$-induced nasal polyps in vitro, more research needs to be carried out in order to determine how these two pathways regulate this process. In this study, we found that both SB203580 and SP600125 can influence the expression of GR isoforms, but blocking the p38 MAPK signal pathway with SB203580 cannot change the expression of a key enzyme in the JNK pathway, and vice versa. The above evidence indicates that the two signal pathways involved in regulating GR expression operate in parallel, and there was no significant interaction observed. Our study also found that SB203580 has a more significant effect on GR isoform expression and GC affinity than SP600125, suggesting that the p38 MAPK may be a more important pathway than the JNK pathway.

In contrast to the results of our own experiments described above, a recent study by Zijlstra and colleagues [27] reported that GR expression and GC sensitivity in IL-17-induced bronchial epithelial cells (16HBE) were regulated through the phosphoinositide-3-kinase (PI3K) pathway, and not through the p38 MAPK and ERK signal pathways. Another study by Miller et al. [28] on GC sensitivity in clones of the human acute lymphoblastic CEM cell line confirmed that the JNK, p38 MAPK, ERK and PKC signal pathways were all involved in GR signal transduction in CEM cells, with JNK and ERK being the main upstream pathways and the p38 MAPK and PKC pathways playing a minor role. To further validate the involvement of PI3K, ERK and PKC signal transduction pathways in regulating GR expression and GC resistance in IL-1 $\beta$-induced nasal polyps in vitro, the specific inhibitors of these pathways were used to block signal pathways in this study. No noticeable changes of GR isoforms and GC affinity were observed after PI3K, ERK or PKC pathways were blocked, which suggests that these pathways were not involved in the regulation of GR expression and GC sensitivity in the IL- $1 \beta$-induced nasal polyps in vitro. Based on the aforementioned 
studies and our own present investigation, we believe that these results on one hand demonstrate the complexity of the signal transduction mechanisms involved in regulating the GR isoforms, and on the other, highlight that the upstream signal pathways of GR and their network have obvious tissue specificity and inducer specificity. Different tissues, induced by different cytokines, may regulate GR isoform expression via different signal transduction pathways. Therefore, we propose that only by further investigating the specific upstream signal transduction pathways involved in GR regulation in a CRS mucosal inflammation environment will it be possible to improve the treatment effect of GC resistance in CRS by targeting its specific signal pathways.

\section{Conclusions}

In summary, our study showed that the p38 MAPK and JNK signal pathways are involved in regulating the expression of GR isoforms in IL-1 $\beta$-induced nasal polyps in vitro, as their activation resulted in a decrease of $G R \alpha / G R \beta$ ratio. Further, our results suggest that these two pathways are involved in the etiology of GC-resistant CRS. Our findings also provide deeper insights into the pathogenesis of $\mathrm{GC}$ resistance in CRS and provide further clues as to which pathways should be targeted in developing a more precise treatment for GC-resistant CRS. However, the precise upstream signal mechanisms involved in GR regulation are very complex. In this study, only five signal pathways were investigated. A complete elucidation of the pathological mechanisms of GC-resistant CRS requires further thorough study on all other related pathways.

\section{Abbreviations \\ GR: Glucocorticoid receptor; GC: Glucocorticoid; CRS: Chronic rhinosinusitis; MAPK: Mitogen activated protein kinase; IL-1 $\beta$ : Interleukin-1 beta.}

\section{Competing interests}

There are no relevant financial interests or competing interests involved in the study on which this manuscript is based.

\section{Authors' contributions}

ZW, PL and QZ conceived the study and designed the experiments; ZW, PL, $H L, J L$ and $J S$ performed experiments and/or participated in data analysis and interpretation; ZW and QZ wrote the manuscript. All authors read and approved the final manuscript.

\section{Authors' information}

Zhenlin Wang and Peng Li are co-first authors.

\section{Acknowledgements}

This work was supported by a research grant from the National Natural Science Foundation of China (81170894), the Beijing Natural Science Foundation (7113156) and a special fund of the high-level health technology personnel development in the Beijing health system (2013-3-093).

\section{Author details}

${ }^{1}$ Department of Otolaryngology-Head and Neck Surgery, Xuan Wu Hospital, Capital Medical University, 45 Changchun Street, Xicheng District, Beijing 100053, PR China. ${ }^{2}$ Department of Otolaryngology-Head and Neck Surgery, The Third Affiliated Hospital of Sun Yat-sen University, 600 Tianhe Street, Tianhe District, Guangzhou 510630, PR China.
Received: 21 August 2014 Accepted: 18 December 2014

Published online: 20 January 2015

\section{References}

1. Hamilos DL. Chronic rhinosinusitis: epidemiology and medical management. J Allergy Clin Immunol. 2011;128:693-707.

2. Wang X, Cutting GR. Chronic rhinosinusitis. Adv Otorhinolanyngol. 2011;70:114-21.

3. Joe SA, Thambi R, Huang J. A systematic review of the use of intranasal steroids in the treatment of chronic rhinosinusitis. Otolaryngol Head Neck Surg. 2008;139:340-7.

4. Cope D, Bova R. Steroids in otolaryngology. Laryngoscope. 2008;1 18:1556-60.

5. Fokkens WJ, Lund VJ, Mullol J, Bachert C, Alobid I, Baroody F, et al. EPOS 2012: European position paper on rhinosinusitis and nasal polyps 2012: a summary for otorhinolaryngologists. Rhinology. 2012;50:1-12.

6. Pujolsa L, Mullol J, Picado C. Glucocorticoid receptor in human respiratory epithelial cells. Neuroimmunomodulation. 2009;16:290-9.

7. Li P, Li Y, Li YQ, Yang QT, Zhang GH. Glucocorticoid receptor expression and glucocorticoid therapeutic effect in nasal polyps. Clin Invest Med. 2010;33:E181-8.

8. Liberman AC, Druker J, Garcia FA, Holsboer F, Arzt E. Intracellular molecular signaling: basis for specificity to glucocorticoid anti-inflammatory actions. Ann N Y Acad Sci. 2009;1153:6-13.

9. Strehl C, Spies CM, Buttgereit F. Pharmacodynamics of glucocorticoids. Clin Exp Rheumatol. 2011;29:S13-8.

10. Pujols L, Alobid I, Benitez P, Martinez-Anton A, Roca-Ferrer J, Fokkens WJ, et al. Regulation of glucocorticoid receptor in nasal polyps by systemic and intranasal glucocorticoids. Allergy. 2008;63:1377-86.

11. Takeda K, Takeno S, Hirakawa K, Ishino T. Expression and distribution of glucocorti... [Auris Nasus Larynx. 2010] - PubMed - NCBI, vol. 2013. 2013.

12. Aversa S, Ondolo C, Abbadessa G, Piccione F, Carriero V, Fulcheri A, et al. Steroid resistance in nasal polyposis: role of glucocorticoid receptor and TGF-beta1. Rhinology. 2012;50:427-35.

13. Szatmary Z, Kebis A. Promoter-context as a determinant of glucocorticoid receptor-responsiveness to activation of p38 and JNK mitogen-activated protein (MAP) kinases. Gen Physiol Biophys. 2012;31:309-22.

14. Kuntzsch D, Bergann T, Dames P, Fromm A, Fromm M, Davis RA, et al. The plant-derived glucocorticoid receptor agonist Endiandrin A acts as co-stimulator of colonic epithelial sodium channels (ENaC) via SGK-1 and MAPKs. PLoS One. 2012;7:e49426.

15. Hu A, Josephson MB, Diener BL, Nino G, Xu S, Paranjape C, et al. Pro-asthmatic cytokines regulate unliganded and ligand-dependent glucocorticoid receptor signaling in airway smooth muscle. PLoS One. 2013;8:e60452.

16. Fokkens $W$, Lund V, Mullol J. European position paper on rhinosinusitis and nasal polyps. Rhinol Suppl. 2007;2007:1-136.

17. Jankowski R, Schrewelius C, Bonfils P, Saban Y, Gilain L, Prades JM, et al. Efficacy and tolerability of budesonide aqueous nasal spray treatment in patients with nasal polyps. Arch Otolaryngol Head Neck Surg. 2001;127:447-52.

18. Tan L, Rogers TJ, Hatzirodos N, Baker LM, Ooi E, Wormald PJ. Immunomodulatory effect of cytosine-phosphate-guanosine (CpG)-oligonucleotides in nonasthmatic chronic rhinosinusitis: an explant model. Am J Rhinol Allergy. 2009;23:123-9.

19. Bonnans C, Chanez P, Meziane H, Godard P, Bousquet J, Vachier I. Glucocorticoid receptor-binding characteristics in severe asthma. Eur Respir J. 2003;21:985-8.

20. Robertson S, Rohwer JM, Hapgood JP, Louw A. Impact of glucocorticoid receptor density on ligand-independent dimerization, cooperative ligand-binding and basal priming of transactivation: a cell culture model. PLoS One. 2013;8:e64831.

21. Furukido K, Takeno S, Ueda T, Yajin K. Cytokine profile in paranasal effusions in patients with chronic sinusitis using the YAMIK sinus catheter with and without betamethasone. Eur Arch Otorhinolaryngol. 2005;262:50-4.

22. Tuszynska A, Krzeski A, Postuba M, Paczek L, Wyczalkowska-Tomasik A, Gornicka B, et al. Inflammatory cytokines gene expression in bone tissue from patients with chronic rhinosinusitis- a preliminary study. Rhinology. 2010;48:415-9.

23. Raddatz D, Toth S, Schworer H, Ramadori G. Glucocorticoid receptor signaling in the intestinal epithelial cell lines IEC-6 and Caco-2: evidence of inhibition by interleukin-1 beta. Int J Colorectal Dis. 2001;16:377-83.

24. Engler H, Bailey MT, Engler A, Stiner-Jones LM, Quan N, Sheridan JF. Interleukin-1 receptor type 1-deficient mice fail to develop social stress-associated glucocorticoid resistance in the spleen. Psychoneuroendocrinology. 2008:33:108-17.

25. Rider CF, King EM, Holden NS, Giembycz MA, Newton R. Inflammatory stimuli inhibit glucocorticoid-dependent transactivation in human pulmonary 
epithelial cells: rescue by long-acting beta2-adrenoceptor agonists. J Pharmacol Exp Ther. 2011;338:860-9.

26. Budziszewska B, Szymanska M, Leskiewicz M, Basta-Kaim A, Jaworska-Feil L, Kubera $\mathrm{M}$, et al. The decrease in JNK- and P38-MAP kinase activity is accompanied by the enhancement of PP2A phosphate level in the brain of prenatally stressed rats. J Physiol Pharmacol. 2010;61:207-15.

27. Zijlstra GJ, Ten HN, Hoffmann RF, van Oosterhout AJ, Heijink IH. Interleukin-17A induces glucocorticoid insensitivity in human bronchial epithelial cells. Eur Respir J. 2012;39:439-45

28. Miller AL, Garza AS, Johnson BH, Thompson EB. Pathway interactions between MAPKs, mTOR, PKA, and the glucocorticoid receptor in lymphoid cells. Cancer Cell Int. 2007;7:3.

\section{Submit your next manuscript to BioMed Central and take full advantage of:}

- Convenient online submission

- Thorough peer review

- No space constraints or color figure charges

- Immediate publication on acceptance

- Inclusion in PubMed, CAS, Scopus and Google Scholar

- Research which is freely available for redistribution 